\title{
DIREITOS ANIMAIS: ZOOLÓGICOS COMO PRÁTICA COLONIAL HUMANA
}

\author{
ANIMAL RIGHTS: ZOOS AS HUMAN COLONIAL PRACTICE
}

Recebido: 27.04 .2020

\author{
Raquel Fabiana Lopes Sparemberger \\ Pós-doutora em Direito pela Universidade Federal \\ de Santa Catarina . Doutora em Direito pela \\ Universidade Federal do Paraná. Professora do \\ Programa de Mestrado em Direito da Universidade \\ Federal do Rio Grande - FURG. Professora \\ pesquisadora do CNPq e FAPERGS. \\ E-MAIL: fabiana7778@hotmail.com \\ LATTES: http://lattes.cnpq.br/1275535624435246 \\ ORCID: https://orcid.org/0000-0001-9366-9237
}

Aprovado: 06.05.2020

\author{
Isabela Peixer Galm Bernardes \\ Mestranda em Direito e Justiça Social na \\ Universidade Federal do Rio Grande - FURG. \\ E-MAIL: isabelagalm@gmail.com \\ LATTES: http://lattes.cnpq.br/1447713961034116 \\ ORCID: https://orcid.org/0000-0001-9763-3039
}

RESUMO: Diante das barreiras do Direito posto, que toma como orientação o paradigma colonial da humanidade, reflexões acerca dos animais não-humanos são necessárias para que se possa transcender a significação clássica de animais enquanto propriedade, já que não se pode continuar a mercê de tradicionais comportamentos humanos que insistem numa arbitrária hierarquização de vidas igualmente sencientes. Objetivou-se no decorrer do texto demonstrar a relação de colonialidade presente no tratamento entre humanos e animais nãohumanos, resultado do paradigma especista da humanidade, responsável por subjugar animais não-humanos e reduzi-los ao status de coisa inanimada. Contudo, argumenta-se ser possível compreender o animal não-humano enquanto ser sujeito de direitos a partir de justificativas ético-filosóficas encontradas nas obras de Tom Regan e Peter Singer, autores expoentes da Ética Animal. Ademais, apresenta-se a necessidade de um esforço do Direito para passar a enxergar o Outro, diferente do humano também enquanto ser sujeito de direitos a partir de compreensões descoloniais da norma, sobretudo no que se refere à Carta Constitucional de 1988 e à lei federal $n^{\circ} 7.173 / 1983$, que dispõe sobre o estabelecimento e funcionamento de jardins zoológicos.

PALAVRAS - CHAVE: Direitos animais; Sujeitos de direitos; Zoológicos; Especismo.

\begin{abstract}
Faced with the barriers of the Law, which takes as its orientation the colonial paradigm of humanity, reflections on non-human animals are necessary so that the classical meaning of animals as property can be transcended, since one cannot continue at the mercy of traditional human behaviors that insist on an arbitrary hierarchy of equally sentient lives. Throughout the text, the aim was to demonstrate the coloniality relationship present in the treatment between humans and non-human animals, resulting from the speciesist paradigm of humanity, responsible for subjugating non-human animals and reducing them to the status of inanimate things. However, it is argued that it is possible to understand the non-human animal as being subject to rights from ethical-philosophical justifications found in the works of Tom Regan and Peter Singer, leading authors of Animal Ethics. In addition, there is a need for an effort of the Law to see the Other, different from the human also as a subject of rights from
\end{abstract}


descolonial understandings of the norm, particularly with regard to the 1988 Constitutional Charter and the federal law $\mathrm{n}^{\circ} 7,173 / 1983$, which provides for the establishment and operation of zoos.

KEYWORDS: Animal Law; Subjects to rights; Zoos; Speciesism.

SUMÁRIO: 1 Introdução 2 Colonialidade da compreensão: o animal não-humano como "nãosujeito" 3 Justificativas ético-filosóficas para se considerar animais não-humanos enquanto sujeitos de direitos 4 Compreensão descolonial dos animais não-humanos na esfera jurídica brasileira 5 O que há de errado em aprisionar $\mathbf{6}$ Considerações finais $\mathbf{7}$ Referências $\mathbf{8}$ Notas de Referências

\section{Introdução}

Imerso no paradigma que insiste em perpetuar a espécie humana como ser excelso entre todos os seres, o Direito tradicionalmente entende que animais não-humanos não são e não podem ser considerados sujeitos de direito. No entanto, a urgência da discussão acerca da crueldade animal perpassa inegavelmente pela compreensão jurídica do que se entende ou não como crueldade animal. O Direito não caminha só, por isso, para que se busque um novo olhar sobre animais não-humanos a discussão atravessa outras áreas do conhecimento, tornando possível reclamar a esses animais condições mínimas de existência.

A abordagem se concentrará sobre o aprisionamento animal em jardins zoológicos enquanto prática colonial humana, haja vista ser mais um espaço onde são perpetuados atos de crueldade animal que, atingido pela miopia moral, não permite à espécie humana enxergar as condições de exploração às quais animais não-humanos são submetidos. Propõe-se, diante da transgressão de direitos animais em razão da exposição em jardins zoológicos, o reconhecimento dos animais não-humanos enquanto sujeitos de direito a partir de duas teorias da Ética Animal, quais sejam o utilitarismo-consequencialista de Peter Singer e a teoria não consequencialista de Tom Regan.

Após abordados os argumentos pelos quais torna-se possível encarar animais não humanos enquanto sujeitos de direitos, parte-se para a necessidade de uma nova abordagem jurídica que tenha como foco a descolonialidade da norma. Por fim, conclui-se pela invalidade da lei federal $n^{\circ} 7.173 / 83$, responsável por regular jardins zoológicos, com base no argumento da colonialidade do paradigma especista da humanidade e na interpretação descolonial da norma.

Para cumprir a tarefa a que se propõe, as argumentações desenvolvidas partem não só da Ética Animal, tendo em vista o importante papel da Filosofia de provocação do Direito diante da sua autêntica capacidade de ir além do que está posto, mas também das construções chaves dos estudos da descolonialidade, pois tal viés de compreensão de mundo tem, na afirmação do Outro, a possibilidade de negação da opressão, que se inicia a partir da exterioridade do Outro. No contexto deste trabalho, o Outro é precisamente o animal objetificado pelo humano.

A metodologia que melhor se adequa à pesquisa é o método dedutivo, já que os comentários tecidos ao longo do texto partem de teorias que defendem ou possam defender direitos animais. Esse arcabouço teórico é ferramenta para explicitar a problemática específica do sofrimento animal diante do aprisionamento em jardins zoológicos. Ademais, considerando que a finalidade do método dedutivo é explicar o conteúdo das premissas ${ }^{1}$, a proposta dos argumentos aqui apresentados é decifrar os enunciados principais trabalhados: a) animais nãohumanos são seres sujeitos de direitos; b) animais não-humanos não são enxergados enquanto sujeitos de valor intrínseco por conta do paradigma especista da humanidade; e c) a lei federal $\mathrm{n}^{\circ} 7.173 / 83$ é inválida pois viola a vedação da crueldade animal. A partir da pesquisa 
bibliográfica enquanto técnica de pesquisa adotada, as explanações aqui levantadas são argumentos críticos ao paradigma da humanidade na tentativa de fundamentar a equiparação de animais humanos e não-humanos enquanto seres dotados de valor intrínseco. Manifestado no contexto do Direito, este texto é um convite à reflexão, pois aborda a necessidade de ampliação da compreensão jurídica dos animais não-humanos, procurando aproximar o mundo jurídico de outras áreas do conhecimento para que seja possível ao Direito enxergá-los como seres sujeitos de direitos através de um tensionamento da ciência jurídica.

\section{Colonialidade da compreensão: animal não-humano como "não-sujeito"}

A condição de possibilidade de alteração do modo de pensar e, consequentemente, das práticas humanas, sempre se sujeita às reflexões, questionamentos e críticas do que outrora foi anunciado como certo e errado. Assim, discutir o status imposto aos animais não-humanos e as consequências jurídicas advindas dessa relação, não poderiam iniciar de outro modo que não expondo, ainda que parcialmente, as origens da sobreposição de espécies, estrutura na qual o humano se sobressai. Importa ressaltar que os apontamentos serão feitos a partir das concepções filosóficas ocidentais.

Parte-se do que foi dito no passado para entender o presente e explicar o que vem a ser o especismo, principal decorrência do paradigma da humanidade (ainda não superado) e a relação de colonialidade estabelecida entre animais humanos e não-humanos. Ao longo do tempo, as relações de cooperação e convivência entre humanos e animais mostraram-se indissociáveis e indispensáveis ao equilíbrio da vida natural. No entanto, em razão dos processos evolutivos, o Homo Sapiens transformou tudo ao seu redor: foi capaz de construir de ferramentas a armas potentes, de pequenas aglomerações a megalópoles, criaram o comércio, a agricultura e a domesticação de animais não-humanos e a partir daí os vínculos com as demais espécies foram esquecidos, negados, subjugados e o uso de animais não-humanos passou a ser normal e socialmente aceito.

A relação de subalternização, em que o humano sujeita animais não-humanos para sua alimentação, vestimenta e diversão é reconhecida como especista ${ }^{2}$. Por "especismo" pode-se entender como o conjunto de pensamentos, doutrinas e práticas que tem como ponto de partida a crença de que animais não-humanos não possuem nenhuma dignidade moral por serem desprovidos de elementos supostamente exclusivos da espécie humana, sobretudo a racionalidade e autoconsciência; é a exclusão fundada apenas na espécie. Pode-se dizer ainda que, a partir da lógica especista, o animal não-humano tem valor na medida em que é útil à espécie humana ${ }^{3}$.

A filosofia grega cuidou de desenvolver as fundamentações da estrutura hierarquizada entre animais humanos e não-humanos, sendo Aristóteles o filósofo expoente na defesa da superioridade humana tal qual hoje se apresenta no pensamento ocidental. A grande cadeia dos seres de Aristóteles trata o universo como ente imutável e organizado num sistema hierarquizado em que cada ser ocupa seu lugar para servir a um propósito permanente ${ }^{4}$. Em resumo, o lugar dos animais não-humanos seria abaixo da espécie humana na escala desse sistema hierárquico para que pudessem servi-la, vez que humanos são seres dotados da capacidade de discernir, de livre vontade, na busca do melhor meio de vida que lhe aprouver ${ }^{5}$.

Apesar de Aristóteles fundamentar a segregação de indivíduos, dispondo a espécie humana de um status privilegiado dentro do sistema consolidado hierarquicamente, não quer dizer que o filósofo não se importava com animais ou que assentia aos maus tratos deferidos aos animas não-humanos. Para Aristóteles, a condição de animalidade era inerente à espécie humana, porém tal semelhança não era suficiente para pensar em igualdade entre espécies, 
uma vez que apenas homens " (do sexo masculino, grego e livre - representando a significação de humanitas) possuía as capacidades contemplativa e racional, que o elevava a um status superior - diminuindo, por consequência, os demais a status inferior" ${ }^{\prime 6}$.

A partir da ética pensada pela lógica aristotélica, é insensato impor ao animal qualquer tipo de violência, tendo em vista que esse animal é algo pertencente a alguém, o que acarreta deveres indiretos ao animal não-humano, não pela sua individualidade considerada em si mesma, mas sim pelo status conferido ao animal não-humano de propriedade ${ }^{7}$. A insensatez de violentar o animal não decorre do dano causado ao animal, mas sim por ser um dano ocasionado à propriedade do humano.

Ainda dentro do recorte do tratamento conferido aos animais não-humanos pelos humanos, dando um salto histórico, passa-se a analisar a baixa Idade Média, pois é o momento inicial de construção da filosofia moderna, fase em que o antropocentrismo renasce e o homem ganha novamente destaque no universo moral. É a partir das noções da filosofia moderna que as relações entre o homem e natureza ganham dimensão de meio/fim, estritamente funcional. Em decorrência da compreensão homem versus natureza, esta última passa a ser vista como recurso eternamente renovável e disponível ao homem. Tem-se aqui o modelo científico moderno antropocêntrico que intensificou a ética aristotélica quanto à sobrevalorização do humano e desvalorização do que não fosse de seu interesse. O Renascimento trouxe à tona a perpetuação do especismo imposto aos animais não-humanos pela espécie humana, estimulando continuamente o pensar da moralidade a partir do homem como centro do universo e medida de todas as coisas, bem como desígnios de sua dignidade e sua liberdade ${ }^{8}$.

A formação moral do ocidente " é signatária da concepção aristotélica, antropocêntrica e hierárquica, típica da racionalidade escravocrata" ${ }^{\prime 9}$, que concebe animais não-humanos moral e juridicamente apenas enquanto propriedade ${ }^{10}$. A herança da ética aristotélica, que acompanha a formação moral e jurídica do ocidente, revela que proteção dos animais não-humanos pelos humanos é diretamente proporcional ao alcance do interesse deste último. Não se protege animais enquanto sujeitos de uma vida, seres com valor intrínseco, "porque a condição de propriedade dos animais é sempre uma boa razão para não se conferir tratamento semelhante a eles, a menos que fazer isso beneficie os proprietários"11.

Aristóteles foi um dos responsáveis pela justificação e defesa de um sistema de mundo hierarquicamente organizado, consolidando o paradigma ${ }^{12}$ humanista, principal mantenedor da ideologia especista, pois visualizava somente uma relação natural e finalística entre humanos e demais seres vivos. Dessa maneira, o que se questiona é a continuidade da adoção irreflexiva de um paradigma (modelo a ser seguido universalmente, cujos argumentos contrários normalmente são sufocados) que irracionalmente escraviza outros seres vivos, fundamentandose exclusivamente na espécie ${ }^{13}$.

Dessa maneira, é possível traçar o aspecto colonial existente na relação entre animais humanos e não-humanos. Ainda que a colonialidade seja originalmente discutida em temas cujo foco sejam as relações humanas, acredita-se que tal argumento pode ser trazido também para o debate nas relações entre animais humanos e não-humanos, tendo em vista o preceito da subalternidade de um grupo e a supervalorização de outro.

A colonialidade decorre do colonialismo, porém, faz-se necessária a diferenciação a fim de delimitar a discussão que se pretende estabelecer. O colonialismo relaciona-se à lógica de exploração e dominação histórica, política e cultural, submetendo uma determinada visão de mundo como sendo a ideal a povos supostamente inferiores por não adotarem o mesmo modo de pensar o mundo ao seu redor. O colonialismo busca imprimir uma universalidade ideológica partindo dos ideais dos povos dominantes. Já a colonialidade atenta "sobre as continuidades históricas entre os tempos coloniais e o tempo presente e também para assinalar que as relações coloniais de poder estão atravessadas pela dimensão epistêmica" ${ }^{14}$.

17 | Revista Brasileira de Direito Animal, e -issn: 2317-4552, Salvador, volume 15, n. 03, p.14-30, Set - Dez 2020 
Em tempos de modernidade marcada pelo ideário da universalidade, tem-se que a colonialidade é o lado obscuro da modernidade, tendo em vista que a dominação é perceptível justamente no processo de normalização/universalização de práticas responsáveis pela escravização e extermínio do subalterno colonizado, isto é, aqueles que são determinados por critérios de exclusão. $O$ discurso da modernidade e seus pressupostos universais (cristianismo, modernidade, Estado, democracia, mercado, etc.) permitem a perpetuação da lógica da colonialidade (dominação, controle, exploração). Desse modo, a colonialidade se sustenta a partir do imaginário epistêmico da universalidade ${ }^{15}$.

Registra-se que, embora a colonialidade seja trabalhada tradicionalmente em questões relativas à dominação dos povos (a partir de relações humanas, portanto), é possível estabelecer um paralelo entre os conceitos explorados de "colonialismo" e "colonialidade" e a relação humanos-animais. Se se considerar o paradigma da humanidade enquanto um dos pressupostos da universalidade moderna e o animal não-humano como o sujeito subalternizado/colonizado, o que de fato se verifica, conforme se depreende da insuficiente reflexão sobre a dignidade e a liberdade de animais não-humanos, herança da era renascentista que intensificou a ética aristotélica no tocante à centralidade do homem no hipotético sistema de mundo hierarquicamente organizado, tem-se a perpetuação da ideologia especista aonde a exploração e dominação de animais ocorre para atender caprichos humanos ${ }^{16}$.

A compreensão universal de animais não-humanos enquanto status de coisa proporcionada pelo paradigma da humanidade que, recorda-se, coloca o humano como ser soberano na escala de importância de seres vivos, não permite que animais não-humanos sejam entendidos como sujeitos de direitos e de valor intrínseco. Ademais, tendo em conta que o paradigma da humanidade atravessa a produção do conhecimento científico, a cultura jurídica moderna não escapa às amarras da colonialidade e está vinculada a uma hermenêutica de reprodução antropocêntrica que somente enxerga o animal enquanto propriedade. Ocorre que não há argumentos plausíveis para essa diferenciação, a não ser o posicionamento especista colonial de inferiorização dos demais seres vivos, para servir aos interesses e caprichos humanos.

\section{Justificativas ético-filosóficas para se considerar animais não-humanos enquanto sujeitos de direitos}

Cumpre agora expor as razões pelas quais o paradigma colonial da humanidade é falho, tornando possível, assim, a superação da universalidade/modernidade, de modo que animais não-humanos possam ser vistos de outro modo para além da condição de subalternos.

O Direito não é um campo isolado da ciência, e, por essa razão, recorre-se à Filosofia, mais especificamente às questões relativas à Ética Animal, uma vez que a Ética está sempre presente quando se tenta justificar racionalmente ações que afetam outros indivíduos. Outrossim, as concepções da Ética Animal são capazes de questionar fundamentadamente a servidão animal, pois quando não se consegue apresentar justificativas razoáveis para subordinação de animais não-humanos, além daquelas baseadas em padrões morais advindos do paradigma da humanidade, é possível rejeitar alegações de que a maioria da espécie humana vive de acordo com padrões éticos, mesmo se aquilo que fazem estiver de acordo com princípios morais convencionais.

Tendo em vista a diversidade de autores cujo objeto de estudo, direta ou indiretamente, envolve a Ética Filosófica, é necessário restringir-se a duas vertentes filosóficas: a) teoria consequencialista-utilitarista, segundo a qual os animais não-humanos importam porque sentem e sofrem, e isso deve ser levado em consideração na tomada de decisões que os atingem, tendo 
Peter Singer ${ }^{17}$ como o autor-referência; e b) teorias não consenquencialistas cujo argumentação pauta-se na importância dos animais não-humanos porque têm subjetividade, e isso, por si só, já Ihes confere o direito a uma existência digna, sendo o autor Tom Regan ${ }^{18}$ representante dessa perspectiva.

A começar pela análise consequencialista, tem-se o foco na análise da qualidade das ações mediante uma verificação do quanto elas favorecem objetivos a serem alcançados. Dentro dessa concepção filosófica, o utilitarismo é a mais conhecida vertente ${ }^{19}$, ainda que o utilitarismo não seja a única teoria abrangida pelo consequencialismo. A partir de uma perspectiva utilitarista, a tomada de decisão por uma ação ou outra depende do grau de satisfação causado por essa ação; a atitude correta é aquela que maximiza o nível de felicidade de todos aqueles que são atingidos por ela. Então, pela visão utilitarista, tudo depende da consequência da ação, por isso fala-se em consequencialista-utilitarista.

Singer desenvolve suas abordagens a partir do utilitarismo preferencial, segundo o qual prevalece o princípio da igual consideração de interesses, que, em síntese, é o posicionamento ético que busca considerar todos os interesses daqueles afetados pela decisão tomada individualmente, o que significa um exercício de empatia, já que as necessidades, vontades e desejos individuais não podem contar mais que as necessidades, vontades e desejos de outra pessoa. Importante ressaltar que para o utilitarismo preferencial não interessa de quem são os outros interesses, já que para a tomada de decisão não se leva em conta qualquer distinção ou diferenciação. Assim, Singer defende que o princípio da igual consideração de interesses não se limita à espécie, pois, como se afirmou, o utilitarismo preferencial não faz discriminações acerca de quem são os interesses, sob pena de tomada de decisão arbitrária. O fato de alguns seres não pertencerem à espécie humana não significa permissão para desconsideração de suas preferências e necessidades.

Outro fator que deve ser pensado em conjunto com os termos do utilitarismo preferencial, além do princípio da igual consideração de interesses, é a senciência. Entendida por Singer como "o único limite defensável da preocupação com interesses alheios" ${ }^{20}$, a senciência deve ser levada em conta, tendo em vista que, independentemente da natureza do ser, o sofrimento deve ser considerado em pé de igualdade até onde é possível fazer comparações aproximadas. Se um animal humano ou não-humano sofre, não há motivos para que sua dor seja desprezada, ao passo que, se não é capaz de sentir/sofrer, não há nada que ser levado em consideração.

Peter Singer também explana uma discussão essencial para o desenvolvimento da construção lógica argumentativa desenvolvida no sentido de fundamentar a atribuição do status jurídico de sujeito de direitos aos animais. Quando se dialoga sobre igualdade de interesses, é inevitável pensar primeiramente em pessoas da espécie humana. No entanto, conforme demonstrado por Singer através do utilitarismo preferencial, os interesses devem ser levados em consideração independentemente da natureza do ser, aplicando-se a condição da senciência. Nesse sentido, cabe questionar o que se entende por pessoa enquanto ser dotado de valor intrínseco.

Para responder a essa pergunta, se pode partir de duas definições sinteticamente aqui abordadas. A primeira, estritamente biológica: humanos são os seres que fazem parte da espécie Homo Sapiens. O outro sentido se dá a partir dos indicadores de humanidade, entre os quais encontra-se autoconsciência, autocontrole, senso de futuro e passado, capacidade de se relacionar com outros seres e comunicação. São percepções que, de acordo com a ética aristotélica, diferenciam supostamente animais não-humanos de seres da espécie humana. Esses dois sentidos de ser humano/pessoa não coincidem: é necessário fazer uma escolha acerca de qual das concepções será adotada. 
No entanto, é por meio da concepção de indicadores de humanidade que normalmente se entende ser humano como pessoa, embora esses termos não sejam equivalentes, pois podem existir pessoas que não sejam da espécie Homo Sapiens, como também podem haver membros da espécie humana que não são pessoas. Isso se justifica porque pessoa, em última instância, designa o ser que é autoconsciente ou racional ${ }^{21}$.

Se para ser uma pessoa é necessário ser racional e autoconsciente, bebês recémnascidos, seres humanos com grau elevado de deficiência mental ou demasiadamente débeis que carecem de racionalidade, autoconsciência e não consigam se comunicar, não poderiam ser considerados como pessoas e, portanto, não seriam sujeitos de direitos. De modo contrário, já se tem comprovação, por meio de experimentos científicos ${ }^{22}$, que animais não-humanos são dotados de autoconsciência, percepção de outros de sua espécie, desenvolvimento de linguagem própria, além de serem capazes de desenvolver raciocínio lógico, incluindo aí a resolução de problemas simples, apresentarem noção de passado e futuro e trabalho em grupo, capacidades essas algumas vezes até maiores do que crianças humanas em tenra idade e humanos com grau elevado de deficiência mental apresentam.

Certamente, essas capacidades se dão em grau inferior diante do aperfeiçoamento da espécie humana ao longo do tempo. Contudo, o ponto é que se pessoa significa ser racional e autoconsciente e animais não-humanos apresentam essas capacidades em maior ou menor grau, eles também devem ser considerados sujeitos de direitos.

A partir dessa (des)construção do conceito de pessoa, é possível dizer que aqui reside uma das maiores falhas do paradigma da humanidade, tendo em vista que ao adotar o critério da racionalidade e autoconsciência para designar quais seres possuem direitos e valores intrínsecos, não atende satisfatoriamente o fato de que alguns seres humanos não são autoconscientes, ao passo que alguns animais não-humanos são capazes de desenvolver comportamentos racionais. É importante ressaltar que não se está reduzindo o status de sujeito de direitos de seres humanos. As explanações aqui levantadas são argumentos críticos ao paradigma da humanidade na tentativa de fundamentar a equiparação de animais humanos e não-humanos enquanto seres dotados de valor intrínseco.

Apesar de a concepção consequencialista-utilitarista apresentar argumentos suficientemente convincentes para se considerar animais não-humanos sujeitos de direitos, há outra vertente filosófica, mais contundente e subjetiva, que também é capaz de identificar nos animais não-humanos valores inerentes merecedores de total respeito. Essa nova abordagem é apresentada por Tom Regan, filósofo defensor da Ética Animal por meio do abolicionismo animal e da visão dos direitos, segundo a qual animais não-humanos importam porque têm subjetividade, o que, por si só, já lhes seria devido o reconhecimento enquanto sujeitos de direitos.

Regan contrapõe o posicionamento de Singer, pois entende que no utilitarismo preferencial, ainda que sejam considerados os interesses de todos os envolvidos, se pode chegar a conclusões que não são necessariamente as melhores para cada indivíduo. Embora também seja possível encontrar respaldo em sua teoria para a ressignificação do termo pessoa (argumentando que animais não-humanos são incapazes de fazer tudo o que um humano em suas plenas faculdades física e mental consegue fazer, porém muitos humanos também não conseguem realizar essas mesmas atividades por não possuírem todas as habilidades necessárias para tanto), Regan questiona principalmente a questão de a teoria utilitarista ser cumulativa, isto é, os interesses e frustações devem ser somados, o que em última instância justifica o fato de a teoria utilitarista atentar apenas para as consequências, pois "o que tem valor para o utilitarista é a satisfação do interesse individual, não o indivíduo que tem o interesse ${ }^{23 \prime}$. Assim, um final bom pode justificar meios ruins quando se tenta alcançar determinado objetivo. 
Portanto, o autor reivindica a abolição imediata de qualquer prática exploratória de animais, seja na ciência, na indústria alimentícia, vestuário, caça e zoológicos, independentemente das consequências que o abolicionismo possa causar. Assim, Regan defende a perspectiva do valor inerente, segundo a qual todos que possuem valor intrínseco o tem igualmente, já que o valor como indivíduo é independente da utilidade que o ser pode "dispor". O fundamento da visão dos direitos defendida por Regan são as similitudes físicas e emocionais existentes entre humanos e animais não-humanos, pois cada ser é sujeito de uma experiência de vida e isso já basta para que seja considerado sujeito de direito e adentre num círculo moral, ou seja, assim como humanos, animais não-humanos também desejam desfrutar de bem-estar, perseguir suas preferências e satisfazer seus interesses ${ }^{24}$.

A partir das duas concepções teóricas da Ética Animal aqui apresentadas, quais sejam o utilitarismo preferencial de Peter Singer e o valor inerente de Tom Regan, é possível argumentar pela redefinição do termo pessoa dentro do Direito, a partir de uma significação crítica, "já que não se pode conceber uma consciência jurídica indiferente às diversas formas de crueldade praticada contra os animais" ${ }^{\prime 25}$, sobretudo quando a Filosofia cumpriu e ainda cumpre seu papel em demonstrar a necessidade urgente de alteração de paradigma ou quando já foi capaz de questionar a permanência do modelo colonial no qual a ciência jurídica está imersa, no tocante ao tratamento dispensado aos animais não-humanos, apresentando justificativas no mínimo plausíveis para se conferir aos animais não-humanos o status de ser cujo valor é inerente.

\section{Compreensão descolonial dos animais não-humanos na esfera jurídica brasileira}

Quando se passa a reconhecer animais não-humanos enquanto sujeitos de direitos, seja pelo do critério da senciência, seja a partir da visão de direitos, o próximo passo é definir por quais direitos os animais não-humanos são abraçados e protegidos juridicamente. É certo que o Direito é originalmente antropocêntrico, já que foi criado pelos e para os humanos e que o paradigma colonial da humanidade prepondera nas relações jurídicas, pois "a natureza jurídica dos mesmos [dos animais] em nossa legislação constitui um grande obstáculo para um raciocínio diferente daquele que está arraigado na consciência popular, ou seja, o animal é um bem, seja da coletividade, seja propriedade particular" ${ }^{26}$. Nesse sentido, muitos juristas afastam a ideia de que animais não-humanos possam ser considerados sujeitos de direitos a partir da Constituição Federal de 1988, sob o argumento de que há uma relação indissociável entre o poder econômico, o bem ambiental e o lucro. Contudo, é possível identificar instrumentos jurídicos basilares para a defesa animal na própria Carta Constitucional de 1988, a partir de uma análise descolonial e não especista da norma, sem deixar de lado os argumentos da Filosofia no campo da ética animal.

Ressalta-se desde já que trazer animais não-humanos para a mesma esfera de consideração moral e, em consequência disso, reconhecer a existência e defender a aplicação de direitos animais, não significa dizer que direitos humanos são menos importantes ou que devam ser desconsiderados. Se trata de elevar o grau de consideração dos animais não-humanos e seu status jurídico para além da condição de coisa inanimada que lhes é imposta.

Animais possuem direitos se humanos também os tiverem. Um direito poderá ser invocado exclusivamente por um humano quando todos os sujeitos da espécie humana (e apenas essa espécie) possuírem esse direito, como é o caso do direito ao culto religioso, ao voto, à democracia e ao exercício da cidadania, pois são direitos que independem da senciência, preferências e interesses, uma vez que estão vinculados às atividades de organização social essencialmente humanas ${ }^{27}$. Dito de outra forma, reconhecer direitos aos animais não-humanos não significa que estes serão protegidos pelos mesmos direitos que hoje resguardam a espécie 
humana, em razão da diferença ontológica entre espécies. Em contrapartida, direitos que dizem respeito à vida, à liberdade e ao não sofrimento abrangem tanto animais humanos quanto nãohumanos, em razão de serem sujeitos de uma vida, dotados de valor inerente.

A Constituição Federal de 1988, no Título VIII "Da ordem social”, capítulo VI "Do meio ambiente", em seu artigo $225, \S 1^{\circ}$, inciso VII, inaugura uma abertura à concretização dos direitos animais, tendo em vista que é categórico ao atribuir ao Poder Público a competência para proteção da fauna, sendo vedadas, na forma da lei, as práticas que submetam animais à crueldade $^{28}$.

Apesar das problemáticas que rondam o preceito que abre caminhos para os direitos animais na Constituição Federal de $1988^{29}$, é incontroverso que o dispositivo mandamental constitucional "reconhece que os animais são dotados de sensibilidade, impondo a todos o dever de respeitar-Ihes a vida, a liberdade corporal e a integridade física" ${ }^{30}$, contendo fragmento essencial à instrumentalização da defesa jurídica dos direitos animais, consistente na vedação de crueldade (Art. $225, \S 1^{\circ}$, inciso VII, CRFB/88), sendo, portanto, uma regra constitucional restrita e proibitiva de condutas, não admitindo ponderação ${ }^{31}$. É possível afirmar, ainda, que esse trecho da Constituição Federal se desprendeu do tradicionalismo jurídico antropocêntrico, "tornando materialmente inconstitucionais as leis ordinárias que regulam a exploração dos animais em circos, zoológicos, laboratórios, fazendas ou abatedouros" ${ }^{32}$. Assim, é fato que a proibição de práticas cruéis foi elevada à categoria de norma constitucional.

Para se compreender essa possibilidade de ampliação de direitos e garantias conferidas pela Constituição Federal para além da espécie humana, é necessário um esforço de interpretação do texto constitucional descolonial e não especista, que retira a espécie humana do foco da norma. A descolonialidade, nesse caso, se dá no posicionamento de superação do paradigma da humanidade (pressuposto da universalidade moderna) e no pensar do humano fora do centro de referência, não mais como ser supremo entre todos os seres. É reconhecer que a razão como exclusividade humana foi e é sinônimo de capacidade de domínio ${ }^{33}$ que não mais se sustenta, porque animais não-humanos fazem parte do meio ambiente e da natureza tanto quanto a espécie humana, porque não são apenas um corpo inanimado a serviço do humano, porque são seres que experienciam uma vida independentemente de sua utilidade e, por isso, devem ser considerados dentro de um mesmo universo ético. A partir de um viés descolonial, se considerarmos que o Direito é um interesse protegido por lei, deve-se admitir que a vedação de crueldade animal constante no artigo $225, \S 1^{\circ}$, inciso $\mathrm{VII}, \mathrm{CRFB} / 88$, é direito próprio do animal não-humano a não ser objeto de crueldade humana, sendo necessário reconhecê-los enquanto sujeitos de direitos.

Embora não haja uma sistematização ou especificação acerca da definição de crueldade na Constituição Federal ou em lei federal ${ }^{34}$, sendo ainda um conceito concebido subjetivamente, o artigo $225, \$ 1^{\circ}$, inciso VII, da Lei Fundamental é claro ao vedar práticas de crueldade aos animais. Isso é suficiente para que um sistema jurídico não especista/antropocêntrico, que efetivamente considerasse animais não-humanos enquanto sujeitos de direito, compreendesse que humanos possuem deveres diretos para com esses animais. Dizer que a espécie humana possui deveres diretos para com os animais não-humanos significa que, para além de uma obrigação moral, há o dever jurídico de não tratar animais com crueldade, obrigação essa de proteção e cuidado reconhecida em norma imperativa direcionada especificamente aos animais não-humanos, sem colocá-los em posição de subalternos ou de propriedade em relação ao ser humano. Quando ocorre atentado ao corpo, à liberdade e à vida, há violação da integridade psíquico-física, da liberdade de locomoção e do direito à vida daquele animal considerado individualmente.

Nesse contexto, retoma-se que embora não haja definição expressa do que seria crueldade no sistema jurídico atual, tem-se que, em razão da vedação constitucional de práticas

22 | Revista Brasileira de Direito Animal, e -issn: 2317-4552, Salvador, volume 15, n. 03, p.14-30, Set - Dez 2020 
cruéis e do necessário reconhecimento do animal no mesmo universo ético da espécie humana, é possível identificar a existência de direitos mínimos a serem garantidos aos animais nãohumanos, sendo alguns deles: a) direito à existência digna; b) à consideração; c) à integridade psíquico-física; d) à liberdade; c) à conservação de seu habitat natural; e d) o direito a não ser objetificado e subalternizado pela espécie humana ${ }^{35}$, além do direito básico de não ser exposto a qualquer prática cruel. Não se trata aqui de uma lista taxativa de direitos animais, mas sim de direitos básicos que possam iniciar a discussão da necessária ressignificação de um sistema jurídico que passe a considerar efetivamente animais enquanto sujeitos de direito ${ }^{36}$.

50 que há de errado em aprisionar

A partir das exposições feitas até aqui para, em primeiro lugar, se considerar animais não-humanos enquanto sujeitos de direitos e, num segundo momento, discutir quais direitos seriam esses, parte-se para o foco do problema que dá título ao texto, tratando-se do aprisionamento animal em jardins zoológicos que, de acordo com a definição legal ${ }^{37}$, são parques abertos ao público com o propósito principal de exibir coleções de animais nãohumanos silvestres vivos mantidos em cativeiro ou em semiliberdade, sendo sua liberdade severamente restrita, portanto.

$\mathrm{Na}$ contramão da efetivação dos direitos animais, a Lei Federal $n^{\circ} .7 .173$, de 14 de dezembro de 1983, que dispõe sobre o estabelecimento e funcionamento de jardins zoológicos, segue a tradicional lógica especista do sistema jurídico brasileiro em relação ao tratamento conferido aos animais não-humanos, categorizando-os enquanto coisas à disposição do humano. Tal afirmativa é verificável a partir de uma leitura dos seguintes dispositivos da referida norma: a) para fins da legislação nacional, jardins zoológicos são quaisquer espaços destinados à coleção de animais mantidos em cativeiro ou em semiliberdade destinados à exposição pública para fins supostamente socioculturais e científicos (artigos $1^{\circ}$ e $2^{\circ}$ ); b) as dimensões das instalações deverão atender a requisitos mínimos de habitação, sanidade e segurança às espécies de animais desde que, ao mesmo tempo, garanta medidas indispensáveis à proteção e conforto do público visitante (artigo $7^{\circ}$ ); c) o vocábulo "exemplares" empregado na qualidade de sinônimo de "animais" é outra evidência de que animais não-humanos são enxergados como coisas inanimadas objetos de negociação (artigos $9^{\circ}, 11$ e 16).

O modo como se denomina um ser facilita seu processo de subalternização e dificulta a sua compreensão em sua própria individualidade. Então, a partir do momento em que um animal dotado de valor intrínseco é enquadrado como mero exemplar de uma coleção; que sua liberdade é cerceada para fins de exposição e divertimento da espécie humana; que as medidas indispensáveis a serem tomadas exigidas em lei são para a proteção do humano e não do animal aprisionado; que esse animal é dispensável, na medida em que pode ser caracterizado como excedente exposto à alienação e permuta, cuja finalidade é a obtenção de lucro, os deveres diretos de cuidado, proteção e respeito à vida são deixados de lado em prol, novamente, da satisfação humana.

Alguns argumentos poderiam ser empregados nesse momento na tentativa de justificar a manutenção de jardins zoológicos. Dentre as principais razões encontram-se a finalidade recreativa e educacional, além do desenvolvimento de pesquisa científica, preservação de espécies e aumento do conhecimento humano sobre determinados animais ${ }^{38}$. No entanto, nenhuma dessas razões parecem ser justificativas razoáveis para ferir os direitos de liberdade, de integridade psíquico-física, de não exposição à crueldade e, em última instância, à vida de uma animal não-humano que, como já foi dito, não são direitos exclusivos da espécie humana.

A primeira hipótese para manutenção de zoológicos - a diversão - é uma das maiores demonstrações do resultado do paradigma da humanidade e da relação de colonialidade que se estabeleceu historicamente entre a espécie humana e os demais animais não-humanos. Nesse 
caso, o aprisionamento do animal não-humano posto à exposição em pequenas celas serve unicamente para um momento de recreação e lazer humanos.

Contudo, a ideia propagandeada de um zoológico não está ligada apenas ao divertimento. Os momentos de lazer vêm acompanhados de estratégias educativas. Isso leva à segunda argumentação comumente utilizada para manutenção de jardins zoológicos: a finalidade educativa. Ocorre que "há poucas evidências que zoológicos têm sucesso em educar pessoas (humanas) sobre os animais" ${ }^{39}$. Certamente não se pode dizer que zoológicos não contribuem para um certo grau de aprendizagem, no entanto, questiona-se aqui qual o conhecimento a ser transmitido a partir de animais enjaulados em espaços infinitamente menores ao seu habitat natural. "Ensinar que uma vida existe dentro de um espaço limitado, apenas para que possamos vê-la quando nos convém não é, nem nunca será, educação ambiental" ${ }^{\prime 40}$.

Há alternativas que podem alcançar os objetivos educacionais de um zoológico (filmes, documentários, palestras, etc.) sem a necessidade de sofrimento animal. Aliás, se a função educativa de manter zoológicos é ensinar sobre os animais e como eles são importantes para o meio ambiente, talvez seria mais interessante exibir jaulas vazias com a consequente explicação do porquê elas estariam assim ${ }^{41}$.

A terceira razão exposta para justificação da manutenção de zoológicos é a realização de pesquisas científicas com as espécies de animais em cativeiro ou em semiliberdade. Esses estudos científicos podem ser divididos em três grandes grupos: pesquisa comportamental, anatômica e patológica. O primeiro ponto a ser considerado é que poucos são os zoológicos que efetivamente contribuem com estudos científicos. Os estudos de comportamento animal feitos em espaços restritos são controversos, tendo em vista que acompanham o animal em um meio ambiente artificial, não havendo razões para se acreditar que dados mais completos sejam extraídos de estudos feitos em zoológicos se comparados com estudos feitos no habitat natural da espécie ${ }^{42}$.

Em relação às pesquisas de anatomia e patologia, estas servem para melhorar as condições de habitação dos zoológicos, para que animais vivam mais tempo e procriem com maior frequência, e assim talvez preservar determinada espécie ${ }^{43}$. Não haveria necessidade de melhorar a qualidade de um zoológico se esses espaços não existissem. $O$ argumento da preservação de espécies em vias de extinção também pode ser aqui questionado, pois é uma solução insuficiente para um problema maior. Não é efetivo manter indefinidamente poucos indivíduos de determinada espécie de animal em cativeiro sendo que seu habitat natural foi degradado ou sem que sejam introduzidos ou reintroduzidos na natureza. Ademais, isso será feito a custo da exploração de animais que estão vivos hoje. O problema criado pelo ser humano será resolvido novamente através do sacrifício animal. Se o objetivo finalístico é a preservação, então, o ideal seria "a preservação de um bioma, a preservação da espécie em seu habitat. A preservação da variabilidade genética dentro do grupo. Nada disso se pode conseguir com zoológicos" ${ }^{44}$.

A quarta e última razão levantada aqui para existência de zoológicos é o aumento do conhecimento humano sobre determinadas espécies. Conhecimento é válido, contudo, conhecimento produzido para estudar outras espécies a partir do aprisionamento animal é um sacrifício desnecessário e desmedido, nesse caso. Há interesses que devem ser considerados que não dizem respeito apenas à necessidade humana de produzir e descobrir novas informações sobre o mundo a sua volta. Da mesma forma que o objetivo educativo, há outros modos de estudiosos descobrirem mais sobre animais não-humanos que não os enjaulando em um espaço consideravelmente limitado ${ }^{45}$.

O último levantamento feito pela Associação Brasileira de Zoológicos e Aquários do Brasil (antiga Sociedade de Zoológicos do Brasil) contabilizou cerca de cento e vinte e três parques

24 | Revista Brasileira de Direito Animal, e -issn: 2317-4552, Salvador, volume 15, n. 03, p.14-30, Set - Dez 2020 
nacionais $^{46}$. A quantidade significativa desses espaços tidos como entretenimento que não alcançam os objetivos a que inicialmente se propõem, desrespeita flagrantemente direitos animais básicos (direito à vida, à existência digna; à consideração; à integridade psíquico-física; à conservação de seu habitat natural; e sobretudo o direito à liberdade) reiteradamente.

É de se notar que, de maneira geral, zoológicos não são entendidos como uma violação da vedação da crueldade animal presente no texto constitucional de 1988, sendo sempre apresentadas justificativas para sua manutenção. A ausência de reflexões acerca de outros interesses importantes para além dos interesses da espécie humana motiva a continuidade do aprisionamento animal, ainda que sejam apresentadas alternativas à recreação, educação, pesquisa científica, aumento do conhecimento e preservação de espécies, de modo a não haver motivações razoáveis para sua conservação.

Zoológicos são uma consequência do paradigma colonial da humanidade, uma extensão do domínio da espécie humana para relembrar sua própria superioridade. São instituições onde animais não-humanos são enjaulados por serem o que (quem) são, cujo objetivo finalístico não é o cuidado direcionado ao animal, mas sim a satisfação de caprichos humanos. Restringir a liberdade e pôr em risco a vida de um ser igualmente senciente que deveria ser considerado em sua individualidade, sem motivações razoáveis que justifiquem seu aprisionamento, é um histórico vício antropocêntrico.

\section{Considerações finais}

A partir do exposto acerca da necessidade de compreensão do animal não-humano enquanto sujeito de direitos (e após apresentação de justificativas para tanto), que direitos relacionados à vida não são exclusividade da espécie humana, e que recreação, educação, pesquisa científica, preservação da espécie e produção de conhecimento não são justificativas razoáveis para a manutenção de zoológicos, depreende-se a inadequação, desproporção e desnecessidade desses espaços de aprisionamento animal, pois não proporcionam divertimento, educação, pesquisa e conhecimento científico de maneira satisfatória e, mesmo que assim fosse, põe em questão a desproporcionalidade de realização de tais objetivos: o custo a que espécie humana submete animais não-humanos a dor, sofrimento e isolamento é desmedido, tendo em vista que as necessidades humanas de educação, divertimento, conhecimento e pesquisa científica podem ser preenchidas de outras maneiras.

O artigo $225, \S 1^{\circ}$, inciso VII da CRFB/88 é o marco e fundamento para se pensar a constitucionalização dos direitos animais, bem como repensar a dignidade da pessoa para além do humano, de maneira que legislação infraconstitucional que envolva animais não-humanos não pode ignorar determinação estabelecida pelo constituinte originário. Desse modo, ao assumir uma postura de rompimento ao paradigma da humanidade, rejeitando uma visão unicamente antropocêntrica ao proibir a crueldade animal e conferir deveres diretos à espécie humana, uma interpretação descolonial e não especista da CRFB/88 torna possível a invalidação jurídica da lei federal $\mathrm{n}^{\circ}$. 7.173/83, uma vez que esta viola diretamente o mandamento constitucional de vedação de crueldade animal ${ }^{47}$.

A invalidade jurídica na manutenção de zoológicos está na violação direta e desarrazoada do direito de liberdade do animal não-humano, bem como no desrespeito à sua integridade física e psicológica, impedindo que esse indivíduo viva com dignidade. Por isso, a conservação de parques zoológicos, além de traduzir a colonialidade humana através do paradigma da humanidade sustentado por uma perspectiva de hierarquia entre espécies, viola diretamente o mandamento constitucional de vedação de crueldade animal.

O fato de existirem cento e vinte e três jardins zoológicos expondo animais à visitação pública não serve como justificativa jurídica para legitimação do sofrimento animal, assim como 
a satisfação de uma suposta necessidade humana de educação, divertimento, pesquisa e conhecimento científico também não. $O$ contexto social atual é marcado por redescobertas, exigindo mudanças urgentes no senso comum teórico do Direito. A irreflexão humana acerca de seus atos em busca de atender seus caprichos, "extrapola as necessidades básicas da preservação da vida, e cria uma cultura em que o produto final tem como finalidade única o humano, não somente sua sobrevivência e bem-estar, mas também tradições inúteis [... $]^{48 \prime}$

O processo de alteração de paradigma da humanidade para um paradigma que considere animais não-humanos enquanto seres sujeitos de direitos passa, obrigatoriamente, por um processo de descolonização de interpretação da norma acerca da atribuição de status jurídico desses animais não-humanos a partir do mandamento constitucional da vedação de crueldade animal. Existe aqui, enquanto parte da descolonização do Direito, a necessidade de reconhecer que a espécie humana detém deveres diretos de respeito e proteção para com animais nãohumanos.

A partir do contexto apresentado, a existência de norma que garante a permanência de zoológicos, desconsidera preceito constitucional e atua de modo condescendente com a crueldade animal. Inexistem termos inúteis no texto constitucional, de modo que a interpretação constitucional é a concretização e absorção da realidade. Assim, a partir do momento em que o legislador originário atentou para a vedação da crueldade animal, deixando tal mandamento expresso no texto constitucional, e que a questão dos direitos animais se apresenta como uma demanda cada vez mais aparente no atual contexto social, se faz necessário o Direito se despir de tradições ultrapassadas que impedem abordagens reflexivas acerca do que envolve a crueldade animal, pois a questão dos Direitos Animais é um problema ético que a ciência jurídica não poderá se desvencilhar.

\section{Referências}

BRASIL. Constituição da República Federativa do Brasil (1988). Diário Oficial da União, Poder Executivo, Brasília, DF, 05 out. 1988. Disponível em: http://www.planalto.gov.br/ccivil 03/constituicao/constituicao.htm. Acesso em: 27 jun. 2019.

BRASIL. Constituição (1988). Emenda constitucional no 96, de 6 de junho de 2017. Diário Oficial da República Federativa do Brasil, Poder Executivo, Brasília, DF, 7 jun. 2017. Disponível em: http://www.planalto.gov.br/ccivil 03/constituicao/Emendas/Emc/emc96.htm. Acesso em: 27 jun. 2019.

BRASIL. Congresso Nacional. Câmara dos Deputados. Deputado aponta necessidade de nova legislação para zoológicos. Agência Câmara Notícias, Brasília, 08 ago. 2017. Disponível em: https://www2.camara.leg.br/camaranoticias/noticias/MEIO-AMBIENTE/538804-DEPUTADOAPONTA-NECESSIDADE-DE-NOVA-LEGISLACAO-PARA-ZOOLOGICOS.html. Acesso em: 9 jul. 2019.

BRASIL. Lei $n^{\circ} 7.173$, de 14 de dezembro de 1983. Dispõe sobre o estabelecimento e funcionamento de jardins zoológicos e dá outras providências. Diário Oficial da União, Brasília, 15 dez. 1983. Disponível em: http://www.planalto.gov.br/ccivil 03/LEIS/1980-1988/L7173.htm. Acesso em: 5 jul.2019.

BRASIL. Lei $n^{\circ} 9.882$ de 3 de dezembro de 1999. Dispõe sobre o processo e julgamento da argüição de descumprimento de preceito fundamental. Diário Oficial da União. Brasília, 06 dez. 1999. Disponível em: http://www.planalto.gov.br/ccivil 03/leis/19882.htm . Acesso em: 21 abri. 2020. 
DIAS, Edna C. Os animais como sujeitos de direito. Revista Brasileira de Direito Animal, Salvador, v. 1, n. 1, jul./dez. 2006, p.119-121.

FELIPE, Sonia T. Antropocentrismo, sencientismo e biocentrismo: perspectivas éticas abolicionistas, bem-estaristas e conservadores e o estatuto de animais não-humanos. Revista Páginas de Filosofia, v. 1, n. 1, jan-jul/2009, p. 2-30.

FRANCIONE, Gary L. Animais como propriedade. Revista Brasileira de Direito Animal, Salvador, v. 2, n. 3, jul./dez. 2007, p. 13-15.

GORDILHO, Heron J. de S. Abolicionismo animal: habeas corpus para grandes primatas.

Tradução: Nicole Batista; Elizabeth Bennett. 2 ed., Salvador: EDUFBA, 2017. Disponível em:

https://repositorio.ufba.br/ri/bitstream/ri/26540/1/AbolicionismoAnimal port-ingl-RI-2017-

EDUFBA.pdf. Acesso em 25 abri. 2020.

GREIF, Sérgio. Um pouco de história sobre animais em zoológicos. Projeto GAP Brasil - Proteção aos grandes primatas. São Paulo, 04 out. 2017. Disponível em: https://www.projetogap.org.br/noticia/um-pouco-de-historia-sobre-animais-em-zoologicos/.

Acesso em: 9 jul.2019.

JAMIESON, Dale. Contra zoológicos. Revista Brasileira de Direito Animal, Salvador, v. 3, n. 4, jan./dez. 2008, p. 51-62.

MARCONI, Marina de A.; LAKATOS, Eva Maria. Fundamentos de metodologia científica. 7 ed. São Paulo: Atlas, 2016.

MEDEIROS, Fernanda L. F. de; ROSA, Cássio C. A dignidade da vida e a vedação de crueldade. Revista de Biodireito e Direitos Animais, Curitiba, v.2, n. 2, jul/dez. 2016, p. 1-20.

NACONECY, Carlos M. Ética \& animais: um guia de argumentação filosófica. Porto Alegre: EDIPUCRS, 2006.

ONU. Unesco. Declaração Universal dos Direitos dos Animais, de 27 de janeiro de 1978. Disponível em: https://wp.ufpel.edu.br/direitosdosanimais/files/2018/10/DeclaracaoUniversaldosDireitosdosAn imaisBruxelas1978.pdf. Acesso em: 30 jun. 2019.

PAZZINI, Bianca. A sonegação histórica de direitos animais e a construção do animal como nãosujeito: notas a partir do paradigma da humanidade. Revista de Biodireito e Direito dos Animais, Minas Gerais, v. 1, n. 2, jul./dez. 2015, p. 165-195.

PAZZINI, Bianca. Direitos animais e literatura: leituras para a desconstrução do especismo. Dissertação. (Mestrado em Direito e Justiça Social) - Universidade Federal do Rio Grande FURG, Rio Grande, 2016. Disponível em: https://argo.furg.br/?BDTD11078. Acesso em: 21 abri. 2020.

SANCHEZ, Karine F. Cativeiros de animais para exibição e a educação ambiental: implicações éticas contemporâneas. Tese (Doutorado em Educação Ambiental) - Universidade Federal do Rio Grande - FURG, Rio Grande, 2018, p. 196. Disponível em: https://argo.furg.br/?BDTD11861 Acesso em: 21 abri. 2020. 
SANTA CATARINA (Estado). Lei $n^{\circ}$ 12.854, de 22 de dezembro de 2003. Institui o Código Estadual de Proteção aos Animais. Disponível em:

http://leis.alesc.sc.gov.br/html/2003/12854 2003 Lei.html Acesso em: 12 jun. 2019.

SÃO PAULO (Estado). Lei $n^{\circ}$ 11.977, de 25 de agosto de 2005. Institui o Código de Proteção aos Animais do Estado e dá outras providências. Disponível em: https://www.al.sp.gov.br/repositorio/legislacao/lei/2005/lei-11977-25.08.2005.html. Acesso em: 12 jun. 2019.

SILVA, Tagore T. de A. Direito animal e hermenêutica jurídica da mudança: a inserção da linguagem dos movimentos sociais e um novo significado jurídico. Revista Brasileira de Direito Animal, Salvador, v. 3, n. 4, jan./dez. 2008, p. 247-264.

SINGER, Peter. Ética prática. Tradução: Jefferson Luiz Camargo. 4 ed. São Paulo: Martins Fontes, 2018.

SPAREMBERGER, Raquel F. L. O conhecimento jurídico colonial e o subalterno silenciado: um olhar para o pluralismo jurídico. In: WOLKMER, Antonio C. (Org.); LIXA, Ivone F. M. (Org.). Constitucionalismo, descolonización y pluralismo jurídico en América Latina. Aguascalientes: CENEJUS /Florianópolis: UFSC-NEPE, 2015, p. 195-215.

RIO GRANDE DO SUL (Estado). Lei $n^{\circ} 11.915$, de 21 de maio de 2003. Institui o Código Estadual de Proteção aos Animais, no âmbito do Estado do Rio Grande do Sul. Disponível em: http://www.al.rs.gov.br/legis/M010/M0100099.ASP?Hid Tipo=TEXTO\&Hid TodasNormas=4637 0\&hTexto=\&Hid IDNorma=46370. Acesso em: 12 jun. 2019.

REGAN, Tom. A causa dos direitos dos animais. Tradução de Heron Santana Gordilho. Revista Brasileira de Direito Animal, Salvador, v.8, n.12, jan./abr. 2013, p. 17-38.

ZAFFARONI, Eugenio R. La pachamama y el humano. Buenos Aires: Colihue; Ciudad Autónoma de Buenos Aires: Ediciones Madres de Plaza de Mayo, 2011.

\section{Notas de Referência}

\footnotetext{
${ }^{1}$ MARCONI, Marina de A.; LAKATOS, Eva Maria. Fundamentos de metodologia científica. 7 ed. São Paulo: Atlas, 2016, p. 74.

${ }^{2}$ O termo especismo é criação de Richard Rayder, professor de psicologia da Universidade de Oxford, e foi usada pela primeira vez nos anos 1970 a fim de estabelecer um paralelo entre sexismo e racismo. In: GORDILHO, Heron J. de S. Abolicionismo animal: habeas corpus para grandes primatas. Tradução: Nicole Batista; Elizabeth Bennett. 2 ed., Salvador: EDUFBA, 2017, p. 183.

${ }^{3}$ NACONECY, Carlos M. Ética \& animais: um guia de argumentação filosófica. Porto Alegre: EDIPUCRS, 2006, p. 70 .

${ }^{4}$ GORDILHO, Op. Cit., 2017, p. 187.

${ }^{5}$ FELIPE, Sonia T. Antropocentrismo, sencientismo e biocentrismo: perspectivas éticas abolicionistas, bemestaristas e conservadores e o estatuto de animais não-humanos. Revista Páginas de Filosofia, v. 1, n. 1, janjul/2009, p. 2-30, p. 6.

${ }^{6}$ PAZZINI, Bianca. A sonegação histórica de direitos animais e a construção do animal como não-sujeito: notas a partir do paradigma da humanidade. Revista de Biodireito e Direito dos Animais, Minas Gerais, v. 1, n. 2, jul./dez. 2015, p. 165-195, p. 178.

${ }^{7}$ FELIPE, Op. Cit., 2009, p. 7.

${ }^{8}$ GORDILHO, Op. Cit., 2017, p.190-191.

${ }^{9}$ FELIPE, Op. Cit., 2009, p.3.
}

28 | Revista Brasileira de Direito Animal, e -issn: 2317-4552, Salvador, volume 15, n. 03, p.14-30, Set - Dez 2020 
${ }^{10}$ Importa destacar que a ideia de maltratar e inferiorizar animais ser moralmente errada já era defendida por outros filósofos da Antiguidade, como Pitágoras e Plutarco. No entanto, a concepção aristotélica de que os animais existem a serviço do humano se tornou dominante. GORDILHO, Op. Cit., 2017, p. 223.

${ }^{11}$ FRANCIONE, Gary L. Animais como propriedade. Revista Brasileira de Direito Animal, Salvador, v. 2, n. 3, jul./dez. 2007, p. 13-15, p. 15.

12 A expressão paradigma neste texto, em linhas gerais, é adotada no sentindo de modelo social imperante; forma de organização, comportamento e pensamento socializados que levam à consolidação do especismo, ainda que inconscientemente. PAZZINI, Bianca. Direitos animais e literatura: leituras para a desconstrução do especismo. Dissertação. (Mestrado em Direito e Justiça Social) - Universidade Federal do Rio Grande - FURG, Rio Grande, 2016. Disponível em: https://argo.furg.br/?BDTD11078. Acesso em: 21 abri. 2020.

${ }^{13}$ Registra-se que existem outros paradigmas/modelos que sustentam e reforçam a ideologia especista para além do paradigma humanista apontado. Entre eles, destacam-se o paradigma da transcendência e o paradigma da razão ou racionalidade. Pelo paradigma da transcendência, Deus teria eleito o homem como ser superior da criação, ao menos de acordo com as religiões ocidentais, sobretudo o cristianismo, o que justificaria o uso de animais não-humanos em prol do benefício e comodidade humanos. Em relação ao paradigma da razão ou da racionalidade, a espécie humana se auto intitula a espécie mais importante em razão da adoção do critério do desenvolvimento de sua racionalidade. Apesar da explanação genérica de alguns modelos de justificação do especismo, acredita-se que o paradigma da humanidade consegue abraçar boa parte dos demais padrões de subalternidade animal e, por essa razão, se elegeu o paradigma humanista como o modelo principal de consolidação da ideologia especista. PAZZINI, Op.Cit., 2016, p. 29.

${ }^{14}$ SPAREMBERGER, Raquel F. L. O conhecimento jurídico colonial e o subalterno silenciado: um olhar para o pluralismo jurídico. In: WOLKMER, Antonio C. (Org.); LIXA, Ivone F. M. (Org.). Constitucionalismo, descolonización y pluralismo jurídico en América Latina. Aguascalientes: CENEJUS /Florianópolis: UFSCNEPE, 2015, p. 195-215, p. 196.

${ }^{15}$ Idem, p. 196.

${ }^{16}$ GORDILHO, Op. Cit., 2017, p. 190-191.

${ }^{17}$ SINGER, Peter. Ética prática. Tradução: Jefferson Luiz Camargo. 4 ed. São Paulo: Martins Fontes, 2018.

${ }^{18}$ REGAN, Tom. A causa dos direitos dos animais. Tradução de Heron Santana Gordilho. Revista Brasileira de Direito Animal, Salvador, v.8, n.12, jan./abr. 2013, p. 17-38.

${ }^{19}$ SINGER, Op. Cit., 2018, p. 21.

${ }^{20}$ Idem, p. 88.

${ }^{21}$ Idem, p. 121-122.

${ }^{22}$ Idem, p. 149-158.

${ }^{23}$ REGAN, Op. Cit., 2013, p. 29.

${ }^{24}$ Idem, p. 33.

${ }^{25}$ SILVA, Tagore T. de A. Direito animal e hermenêutica jurídica da mudança: a inserção da linguagem dos movimentos sociais e um novo significado jurídico. Revista Brasileira de Direito Animal, Salvador, v. 3, n. 4, jan./dez. 2008, p. 247-264, p. 251.

${ }^{26}$ DIAS, Edna C. Os animais como sujeitos de direito. Revista Brasileira de Direito Animal, Salvador, v. 1, n. 1, jul./dez. 2006, p.119-121, p. 119.

${ }^{27}$ NACONECY, Op. Cit., 2006, p. 159.

${ }^{28}$ BRASIL. Constituição da República Federativa do Brasil (1988). Diário Oficial da União, Poder Executivo, Brasília, DF, 05 out. 1988. Disponível em: http://www.planalto.gov.br/ccivil 03/constituicao/constituicao.htm. Acesso em: 27 jun. 2019.

${ }^{29}$ Destaca-se que no artigo 225 da CRFB/88 foi incluído o $\$ 7^{\circ}$ pela Emenda Constitucional $\mathrm{n}^{\circ}$. 96/2017, segundo a qual não se consideram cruéis práticas desportivas e culturais que utilizem animais não-humanos, desde que sejam consideradas como patrimônio cultural imaterial brasileiro, regulamentadas por lei específica e que garantam o bem-estar dos animais envolvidos. A inclusão desse parágrafo é considerada controversa pelos animalistas, sobretudo porque enquadra, uma vez mais, animais não-humanos na qualidade de coisa a serviço de entretenimentos culturais organizados em virtude do prazer humano, neste caso. Ademais, nota-se que o conteúdo do parágrafo vai de encontro ao estabelecido no $\$ 1^{\circ}$, inciso VII do artigo $225 \mathrm{da} \mathrm{CRFB} / 88$, tendo em vista tratar-se da sobreposição da cultura humana sobre a vida do animal, desde que lhe seja garantido o bemestar. Deve-se ter em conta ainda que, sob a perspectiva do viés teórico que considera animais não-humanos seres sujeitos de direitos, condutas benestaristas não impedem que sejam aplicadas ao animal práticas cruéis. BRASIL. Constituição (1988). Emenda constitucional no 96, de 6 de junho de 2017. Diário Oficial da República Federativa do Brasil, Poder Executivo, Brasília, DF, 7 jun. 2017. Disponível em: http://www.planalto.gov.br/ccivil 03/constituicao/Emendas/Emc/emc96.htm. Acesso em: 27 jun. 2019.

${ }^{30}$ GORDILHO, Op. Cit., 2017, p. 299. 
${ }^{31}$ MEDEIROS, Fernanda L. F. de; ROSA, Cássio C. A dignidade da vida e a vedação de crueldade. Revista de Biodireito e Direitos Animais, Curitiba, v.2, n. 2, jul/dez. 2016, p. 1-20, p. 15.

${ }^{32}$ GORDILHO, Op. Cit., 2017, p. 299.

${ }^{33}$ ZAFFARONI, Eugenio R. La pachamama y el humano. Buenos Aires: Colihue; Ciudad Autónoma de Buenos Aires: Ediciones Madres de Plaza de Mayo, 2011, p. 17.

${ }^{34}$ Ressalta-se que embora não haja nenhuma lei federal ou mandamento constitucional que defina quais são as práticas cruéis para com os animais, alguns estados da federação elaboraram leis estaduais que visam a proteção animal. O Rio Grande do Sul é um exemplo. A Assembleia Legislativa aprovou a lei estadual 11.915 de 21 de maio de 2003, intitulada Código de Estadual de Proteção Animal. Ocorre que, da leitura da norma, vê-se que o tratamento dispensado aos animais não humanos parte de uma perspectiva benestarista, vez que ao mesmo tempo que proíbe a agressão física aos animais ou qualquer outro tipo de experiência que lhe cause sofrimento (Art. $2^{\circ}$, inciso I, da lei estadual), regula a vivissecção (experiências com animais vivos em laboratórios e centros de pesquisa) desde que o animal seja anestesiado (artigos 18 e 20 da lei estadual). Regula também frigoríficos, abatedouros e matadouros, pois o artigo 16 da referida legislação aponta que o abate de animais "tem a obrigatoriedade do uso de métodos científicos e modernos de insensibilização, aplicados antes da sangria, por instrumentos de percussão mecânica, processamento químico, elétrico ou decorrentes do desenvolvimento tecnológico". Isto é, veda práticas que causam sofrimento ao animal no limite daquilo que for destinado ao proveito humano. Outros estados da federação também contam com leis estaduais que visam a proteção animal pelo viés benestarista, como é o caso do Estado de São Paulo (lei estadual $\mathrm{n}^{\circ}$ Lei $\mathrm{n}^{\circ} 11.977$, de 25 de agosto de 2005) e Santa Catarina (lei estadual $\mathrm{n}^{\circ}$ Lei $\mathrm{n}^{\circ} 12.854$, de 22 de dezembro de 2003).

${ }^{35}$ ONU. Unesco. Declaração Universal dos Direitos dos Animais, de 27 de janeiro de 1978. Disponível em: https://wp.ufpel.edu.br/direitosdosanimais/files/2018/10/DeclaracaoUniversaldosDireitosdosAnimaisBruxelas19 78.pdf. Acesso em: 30 jun. 2019.

${ }^{36}$ PAZZINI, Op. Cit., 2016, p. 108.

${ }^{37}$ BRASIL. Lei $\mathrm{n}^{\circ}$ 7.173, de 14 de dezembro de 1983. Dispõe sobre o estabelecimento e funcionamento de jardins zoológicos e dá outras providências. Diário Oficial da União, Brasília, 15 dez. 1983. Disponível em: http://www.planalto.gov.br/ccivil_03/LEIS/1980-1988/L7173.htm. Acesso em: 5 jul.2019.

${ }_{38}$ JAMIESON, Dale. Contra zoológicos. Revista Brasileira de Direito Animal, Salvador, v. 3, n. 4, jan./dez. 2008, p. 51-62, p. 53.

${ }^{39}$ Idem, p. 54.

${ }^{40}$ SANCHEZ, Karine F. Cativeiros de animais para exibição e a educação ambiental: implicações éticas contemporâneas. Tese (Doutorado em Educação Ambiental) - Universidade Federal do Rio Grande - FURG, Rio Grande, 2018, p. 196. Disponível em: https://argo.furg.br/?BDTD11861 Acesso em: 21 abri. 2020.

${ }^{41}$ JAMIESON, Op. Cit., 2008, p. 55.

${ }^{42}$ Idem, p. 56.

${ }^{43}$ Idem, p. 56.

${ }^{44}$ GREIF, Sérgio. Um pouco de história sobre animais em zoológicos. Projeto GAP Brasil - Proteção aos grandes primatas. São Paulo, 04 out. 2017. Disponível em: https://www.projetogap.org.br/noticia/um-pouco-dehistoria-sobre-animais-em-zoologicos/. Acesso em: 9 jul.2019.

${ }^{45}$ JAMIESON, Op. Cit., 2008, p. 58.

${ }^{46}$ BRASIL. Congresso Nacional. Câmara dos Deputados. Deputado aponta necessidade de nova legislação para zoológicos. Agência Câmara Notícias, Brasília, 08 ago. 2017. Disponível em: https://www2.camara.leg.br/camaranoticias/noticias/MEIO-AMBIENTE/538804-DEPUTADO-APONTANECESSIDADE-DE-NOVA-LEGISLACAO-PARA-ZOOLOGICOS.html. Acesso em: 9 jul. 2019.

${ }^{47}$ Ainda que o foco do texto em questão não seja teoria e aplicação de normas constitucionais, importa ressaltar a possibilidade da invalidade jurídica da lei $\mathrm{n}^{\circ} .7 .173 / 83$ por meio de arguição de descumprimento de preceito fundamental (ADPF), já que a norma é anterior à publicação da Constituição Federal de 1988, podendo-se argumentar pela controvérsia constitucional existente entre lei federal e o texto constitucional, referindo-se ao Art. $225, \S 1^{\circ}$, inciso VII e à lei federal $n^{\circ} 7.173 / 83$ no caso. BRASIL. Lei no 9882 de 3 de dezembro de 1999. Dispõe sobre o processo e julgamento da argüição de descumprimento de preceito fundamental. Diário Oficial da União. Brasília, 06 dez. 1999. Disponível em: http://www.planalto.gov.br/ccivil_03/leis/19882.htm . Acesso em: 21 abri. 2020.

${ }^{48}$ SANCHEZ, Op. Cit., 2018, p. 120. 